\title{
Tecnologias Digitais da Informação e Comunicação na Formação Continuada para Ensino de Estatística: um Estudo em Dissertações e Teses Brasileiras
}

\section{Information and Communication Technologies in Continuing Education for Statistics Teaching: a Study on Brazilian Theses and Dissertations}

\author{
Geisiane Rodrigues dos Santos ${ }^{1 \mathrm{ab}}$; Nielce Meneguelo Lobo da Costa*b

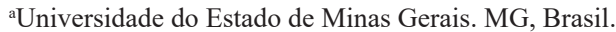

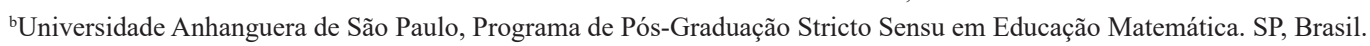 \\ *E-mail: nielce.lobo@anhanguera.com
}

\begin{abstract}
Resumo
No cenário atual de incertezas, este artigo propõe refletir sobre alguns dos impactos da COVID-19 no campo da Educação e o uso das tecnologias da informação. Com o avanço da pandemia, desde os primeiros momentos deparamo-nos, em Educação, com o incômodo de docentes e discentes que enfrentam dificuldades ao lidar com aulas online, ensino a distância (EAD) e tecnologia. Em particular, a utilização de ferramentas tecnológicas é um desafio para docentes, tanto em sua formação inicial como na continuada. Nesse sentido, esta pesquisa de revisão de literatura tem o propósito de identificar as dissertações e teses publicadas na Biblioteca Digital Brasileira de Teses e Dissertações (BDTD) sobre: Formação Continuada, Uso das Tecnologias e Ensino de Estatística. Para isso, foi desenvolvida uma busca com as palavras-chave: "formação continuada", "formação docente", "tecnologia digital", "tecnologia da informação", "ensino de estatística", "aula online" e "ensino híbrido" nas pesquisas disponibilizadas online, compreendidas entre 2002 e 2020 . Constatou-se a existência de 47 pesquisas, entre dissertações e teses, das quais 8 foram selecionadas para análise. A partir da categorização das informações, identificamos as principais Instituições de ensino envolvidas, a metodologia da pesquisa, o referencial teórico e as ferramentas tecnológicas utilizadas na formação docente ou com os alunos. Como conclusão identificamos nas pesquisas analisadas a constatação de que a formação continuada do professor de Matemática tem se apresentado insuficiente e a sugestão é a de que sejam oferecidos cursos como alternativa relacionada às dificuldades no uso das tecnologias aplicadas à Educação.
\end{abstract}

Palavras-chave: Formação Docente. Revisão de Literatura. Ensino Híbrido. Aulas Online. Tecnologia Educativa.

\begin{abstract}
In the present scenery of uncertainties, this article proposes to reflect on some impacts of Covid-19 over Education and the use of information technologies in this context. Due to the spreading of the pandemic, since the first moments we deal with the discomfort of teachers and students that face difficulties at working with online classes, distance learning and technology. Particularly, the usage of technological tools is a challenge for teachers as much as in their pre-service education as in their continuing education. In this sense, this literature review aims to identify, among thesis and dissertations published in the "Biblioteca Digital Brasileira de Teses e Dissertações (BDTD) on: Continuing Education, Usage of technologies and Statistics Teaching. For such, a search was done with the keywords "continuing education", "teacher education", "digital technology", "information technology", "statistics teaching", "online classes" and "hybrid teaching" in the period of 2002 and 2020. It was found 47 researches, among thesis and dissertations, from which 8 was selected for analysis. From the categorization of these information, it was possible to identify the main Institutions involved, the research methodology, the theoretical references and technological tools used in teacher education or in the classroom. As a conclusion, we identified in the research analyzed, that the continuing education of Mathematics teacher has presented itself insufficient and new courses are suggested as an alternative to face the difficulties in the usage of technologies applied to Education.
\end{abstract}

Keywords: Teaching Formation. State of Art. Statistics Teaching. Online Classes. Digital Technology.

\section{Introdução}

Ao longo do tempo, as sociedades contemporâneas vêm sofrendo intensas transformações tecnológicas, as quais impactam a rotina das instituições de ensino por todo o mundo.

Atualmente, mesmo com o avanço da tecnologia, muitas salas de aula têm sido um espaço tradicionalista de ensino, configurado com a centralidade do professor, a lousa ou quadro de giz e o livro. Esse modelo tradicionalista enfrenta uma nova realidade escolar e uma realidade de ensino ainda mais nova diante do cenário atual, que propõe ao professor adquirir competências de uso de tecnologias, criar estratégias para a aprendizagem e adequá-las aos objetivos de ensino.

O cenário atual evidencia os efeitos devastadores da pandemia e da expansão acelerada do número de óbitos por COVID-19 no Brasil e no mundo, o que levou as populações a reações extremas de isolamento social, nas quais todos os setores foram afetados (por exemplo, turístico, entretenimento, comercial, saúde, etc.) e precisaram se adequar à nova realidade de higiene e segurança para combater os avanços do 
vírus. Tais mudanças também afetaram o cenário educacional, que, sem as aulas presenciais, foi obrigado a adentrar na vida online.

Vale destacar que o uso da tecnologia em sala de aula está associado à estrutura física das instituições de ensino, ao papel do professor e sua formação tecnológica, à escolha dos materiais e recursos didáticos utilizados e, principalmente, à competência em lidar com a insegurança frente à nova realidade de ensino.

O que, efetivamente, houve no cenário atual que transformou a sala de aula e consequentemente o trabalho do professor com o uso das tecnologias? O que tem sido feito para capacitar o professor com as tecnologias?

Segundo o Jornal da Vida $(2020)^{2}$, no cenário atual encontramos mais de 1,5 milhões de estudantes sem aulas presenciais e a forma para minimizar esse problema foi o do ensino online, com uso das tecnologias. Essa situação impôs um grande desafio tanto aos professores quanto aos alunos, que precisaram se adaptar e reinventarem-se para enfrentar os novos modelos de ensino.

Segundo Rolando (2017, p. 1), “o uso das TIC no ensino tem sido alvo de numerosas e diversificadas investigações no que diz respeito à aprendizagem dos alunos, à formação e ao exercício profissional de professores", por favorecer e oportunizar a aprendizagem em um ambiente mais interativo e, por essa razão, mais condizente com os atuais paradigmas de ensino, nos quais o professor deixa de ser figura central e abre espaço para maior participação dos alunos.

Assim sendo, para colocar em prática semelhante estratégia de ensino é preciso repensar o conjunto de saberes e competências adquiridos na formação inicial dos professores e a sua consolidação na formação continuada. Isto é, repensar como vêm ocorrendo o percurso formativo destes profissionais de educação, principalmente no tocante à realidade escolar. Por isso, as pesquisas têm se intensificado nos últimos anos devido à velocidade com que ocorrem mudanças no cenário educacional, haja vista a relação direta entre a formação docente, a apreensão e a aplicação tecnológica. Nesse caso, a apreensão do professor não deve ser confundida com o medo do conhecimento teórico adquirido ou da prática pedagógica, e sim da competência em atuar com Tecnologias da Informação e Comunicação (TIC) aliadas ao ensino e a aprendizagem.

Assim sendo, as pesquisas na formação inicial de professores e na formação vem crescendo recentemente, principalmente em face da abordagem do professor frente a um ensino conteudista, com metodologia expositiva e pouco envolvente, apontando a necessidade de se trabalhar com o uso de tecnologias como uma alternativa. Em razão disso, o cenário atual pressiona a escola e as práticas pedagógicas existentes por mudanças e cria expectativas de que novos recursos para aulas online potencializem a construção do conhecimento e o processo de ensino e aprendizagem do aluno.

Para entender como as pesquisas têm avançado nesse contexto, apresentamos neste artigo uma revisão de literatura, que investiga, por meio de revisão bibliográfica, a produção sobre o ensino de Estatística na formação do professor, inicial e continuada, com o uso das tecnologias e, particularmente, com aulas online.

\section{A Formação Docente, Inicial e Continuada}

Ao repensarmos a formação docente com a finalidade de melhorar a qualidade do ensino com o uso das tecnologias, recorremos a discussões que abordam a formação, inicial e continuada, e a necessidade de se estabelecer uma maior relação entre teoria e prática, com o intuito de promover uma transformação significativa na formação pedagógicotecnológica, refletindo os saberes que norteiam a atividade docente.

Como esclarecem Santos e Alves (2020, p.111):

O assunto da formação de professores incentiva discussões na tentativa de procurar opções em relação à construção de um saber docente, que apresente o professor como um ser crítico, reflexivo, criativo, questionador e investigador de sua prática pedagógica.

Assim sendo, a integração das tecnologias ao ensino se mostra essencial na medida em que, a partir do questionamento da própria prática pedagógica, professores podem observar que os métodos e estratégias até então frequentes tornaramse pouco eficazes em um cenário pandêmico, no qual o afastamento da sala de aula pôs em evidência as limitações das formas de ensinar.

Se olharmos ao nosso redor, tanto no contexto educacional quanto fora dele, estamos cercados de tecnologias que influenciam a nossa rotina. No momento atual, há necessidade de os professores se reinventarem para lidar com os problemas do isolamento social e a impossibilidade do contato presencial diário nas escolas, consequentemente, a solução encontrada foi o estabelecimento das aulas totalmente online.

Essa nova situação representa um grande desafio, tanto para os professores, quanto para os alunos. Embora o cenário tecnológico digital não seja assim tão novo, há professores que não sabem lidar com as inovações e ainda ensinam desconectados das tecnologias digitais.

Nesse sentido, Gonçalves e Marco (2020, p. 560) destacam a importância da abordagem das Tecnologias Digitais na formação docente, "de modo a permitir que eles as vivenciem e explorem para que tenham a possibilidade de desenvolver conhecimentos para seu uso e para que se sintam seguros de incorporá-las à sua (futura) prática docente".

Desse modo, os autores supramencionados complementam afirmando a necessidade de formar professores críticos e reflexivos que conheçam as tecnologias digitais, sintam-se 
confortáveis com esses novos instrumentos pedagógicos e possuam autonomia para escolher aqueles que melhor possam auxiliá-los no ensino dos conteúdos matemáticos.

Em 2008, Maltempi salientou a necessidade de interligar fortemente conhecimentos pedagógicos, específicos e tecnológicos na formação docente:

Diante do exposto nas seções anteriores, é possível notar que novas responsabilidades e atribuições são requeridas do professor quando este passa a incorporar tecnologias em suas aulas. No entanto, ao analisar a formação inicial recebida pelos professores, percebo o grande passo que se espera deste profissional. A formação inicial dos cursos de licenciatura em matemática, no geral, pouco mudou nas últimas décadas no que se refere à incorporação das tecnologias na prática docente e, portanto, continua-se formando professores cujo referencial de prática pedagógica é aquele no qual tecnologias não tomam parte (Maltempi, 2008, p. 64).

Assim, o autor já registrava, em 2008, as deficiências na formação inicial quanto à incorporação da tecnologia à prática e, consequentemente, alertava sobre a ocorrência de uma sobrecarga à formação continuada no tocante às tecnologias digitais, cujo foco poderia ser outro. Isso continua sendo verdade atualmente, ainda que tenham se passado 12 anos.

Nesse sentido, Lobo da Costa e Prado (2011) asseveram que, para atender aos anseios da sociedade e da escola com relação aos avanços científicos e tecnológicos, a formação continuada do professor de Matemática tem se apresentado como uma possível solução para sanar lacunas que advêm da formação inicial. Para isso, trabalhos colaborativos buscam ações de formação que tencionam transformações através das quais o professor se torne um ser crítico, reflexivo e investigador de sua própria prática pedagógica.

A formação continuada tem se apresentado hoje como uma necessidade urgente não apenas para complementar ou sanar prováveis deficiências oriundas da formação inicial do professor de Matemática, mas também para atender às demandas decorrentes dos avanços científicos e tecnológicos, os quais caracterizam um novo paradigma de sociedade e, consequentemente, de escola. [...] O professor, por sua vez, vem cada vez mais se deparando com desafios, que se expressam em novas propostas curriculares para a Educação Básica, as quais exigem reconstruções tanto quanto ao seu conhecimento matemático quanto sobre o seu fazer pedagógico, que ocorre no cotidiano da realidade da escolar (Lobo da Costa \& Prado, 2011, p.1).

Nesse contexto, Maltempi (2008) acredita que se deve discutir o uso das tecnologias digitais na formação continuada, promovendo métodos para que o professor incorpore os conteúdos específicos à tecnologia adequada. Porém, se existia ainda alguma resistência do professor em ambientar e incorporar as tecnologias à sua prática docente, o momento social que estamos vivendo dirime qualquer dúvida referente à premência de viabilizar o ensino com auxílio da tecnologia. Isso requer um esforço e mudança de paradigma: o professor precisa, agora, repensar as estratégias didáticas e incorporálas aos processos de ensino e de aprendizagem, segundo Abar e Rodrigues (2020, p. 5), é, mais importante do que o professor dominar as técnicas, o fato de estar apto a construir o percurso com os estudantes, os quais, muitas vezes, já se apropriaram das tecnologias sem saberem utilizá-las em seu cotidiano educacional, é fundamental.

Para isso, os autores ainda ressaltam a importância de se preparar o professor para o uso das tecnologias:

A sala de aula vive, hodiernamente, uma fase de aproveitamento e descobrimento de novos recursos tecnológicos. Entretanto, para que isso possa acontecer de maneira satisfatória e que resulte em bons processos didáticos, não basta apenas equipar as salas de aula com máquinas; é preciso preparar os professores com relação ao conhecimento matemático e ambientá-los às tecnologias disponíveis. O aluno tem condições de aprender quando mobiliza os seus recursos cognitivos e afetivos, com vista a atingir um objetivo do sucesso na aquisição do conhecimento (Abar \& Rodrigues, 2020, p.74).

Diante disso, acreditamos que a formação pedagógicotecnológica do professor apresenta hodiernamente o desafio da preparação para integrar as tecnologias digitais aos processos de comunicação com os alunos e aos processos de mediação do ensino e da aprendizagem.

\section{Metodologia da Pesquisa}

Trata-se de uma pesquisa qualitativa, do tipo pesquisa documental, pois "vale-se de materiais que não receberam ainda um tratamento analítico, ou que ainda podem ser reelaborados de acordo com os objetos de pesquisa" (GIL, 2002, p. 45). A análise é descritiva e interpretativa fundamentada em categorias definidas a posteriori, através das quais são identificados e categorizados os resultados da busca. Assim, entendemos por qualitativa a pesquisa cujo processo consiste em uma "sequência de atividades, que envolve a redução dos dados, a categorização desses dados, sua interpretação e a redação do relatório", conforme Gil (2002, p.133).

Ainda segundo Gil (2002, p.41), é importante destacar a finalidade exploratória desta pesquisa, que tem como "objetivo principal o aprimoramento de ideias ou a descoberta de intuições".

\subsection{Procedimentos metodológicos}

A coleta dos dados foi feita a partir da base de dados da Biblioteca Digital Brasileira de Teses e Dissertações - BDTD, portal público do IBICT ligado ao Ministério da Ciência, Tecnologia, Inovações e Comunicações (www.bdtd.ibict. br/vufind/). Consideramos o corte temporal de 18 anos e identificamos as pesquisas concluídas de 2002 a 2020.

A partir do filtro realizado na base de dados da BDTD, com critérios voltados para a formação docente, ensino de estatística, aula online, tecnologias e ensino híbrido, foram selecionados oito das 47 pesquisas, resultantes desta busca, delimitando o material que esta revisão abrange.

Cada um desses filtros e categorizações representa a união das superposições resultantes da combinação do conhecimento 
dos professores e sua efetiva integração com as tecnologias no ensino com o conhecimento do conteúdo de Estatística e sua representação por meio do uso da tecnologia.

O protocolo desenvolvido para a análise dos dados incluiu identificar: as teorias, os procedimentos de pesquisa, os referenciais teóricos e a contribuição científica de cada pesquisa selecionada.

Para localizar as pesquisas na BDTD, foram utilizados inicialmente os termos:

1) Tecnologia da informação + ensino de estatística + aula online + matemática, os quais localizaram seis pesquisas, com aproveitamento de dois deles no corpus, uma vez que os demais se referiam a outras áreas do conhecimento e sua abordagem excederia os limites do escopo desta pesquisa de revisão.

As duas pesquisas selecionadas foram: Vespasiano (2016) e Baur (2017).

Vespasiano (2016), em sua dissertação intitulada "As tecnologias digitais da informação e comunicação na docência universitária nos cursos de administração e ciências contábeis", investigou o conhecimento, o desenvolvimento da competência pedagógico-digital e a integração das tecnologias digitais na prática de professores do curso de Administração e Ciências Contábeis, na perspectiva do Conhecimento PedagógicoTecnológico de Conteúdo (TPACK), para integração das Tecnologias Digitais de Informação e Comunicação (TDIC) na docência universitária. Com uma abordagem mista, ela realiza uma pesquisa com 47 professores através de um questionário estruturado e entrevistas, os quais são analisados pelo método estatístico multidimensional viabilizado pelo software CHIC - Classificação Hierárquica, Implicativa e Coesiva. Sua análise aponta que o professor que compreende o uso das tecnologias na sua prática docente torna o ambiente mais interativo e dinâmico, porém os cursos realizados pela maior parte dos professores não promovem a integração das TDIC ao ensino e a aprendizagem.

Embora a pesquisa da autora destacou que a maioria dos docentes analisados apresentam domínio de diferentes ferramentas tecnológicas, na prática esses conhecimentos não possuem a abrangência esperada quando se trata da aprendizagem com os alunos de forma integrativa. Ao mesmo tempo, tais conhecimentos tornam-se congruentes quando se leva em consideração a importância da experiência prévia com tecnologia de cada um. Por outro lado, a incongruência se dá em relação à falta de aperfeiçoamento em cursos específicos direcionados à formação continuada que integram, de fato, o uso das TICs ao ensino e a aprendizagem. Assim, Vespasiano pressupõe que a prática docente com o uso da tecnologia seria mais potencializada com o aperfeiçoamento dos docentes. Por fim, a pesquisa apontou que muitos docentes têm o domínio de ferramentas tecnológicas, porém, ainda persiste a necessidade de realizar cursos de formação continuada que integrem o uso das TICs ao ensino e a aprendizagem.

Baur (2017), em sua dissertação intitulada "Investigação
Matemática na aprendizagem da Geometria: conexões entre quadriláteros, triângulos e transformações geométricas", investigou o processo de aprendizagem que desencadeia a construção do conhecimento de geometria, dos conceitos de quadriláteros, triângulos e de Transformações Geométricas (translação, rotação e reflexão), utilizando o software GeoGebra, sob a perspectiva da Investigação Matemática em sala de aula, com alunos do $6^{\circ}$ ano do Ensino Fundamental. Por meio das TCI, os resultados do processo foram armazenados em formulários online. Além disso, também foram utilizadas folhas com atividades, malhas impressas e o applet "Design a Tessellation", recurso online e gratuito. A análise do processo foi realizada na perspectiva dos níveis de Van Hiele e apresentou o progresso realizado pelos estudantes que dela participaram. Assim sendo, o uso das TIC potencializou o ensino e a aprendizagem.

Nesse cenário, embora não tenha sido realizado um curso com o uso das TIC com professores, o estudo de Baur (2017) aponta que a ideia central com o uso adequado das TIC estava voltada para os alunos, empregando um processo de ensino em concordância com a idade e série deles. Em outras palavras, o autor observou que o uso das TIC serviu como estímulo aos alunos e, portanto, contribuiu positivamente para a aprendizagem deles.

Na sequência procedemos à busca na base da BDTD com os termos:

2) Tecnologia digital + ensino de estatística + aula online + matemática, a qual resultou em 8 trabalhos, 5 aproveitados no corpus, uma vez que os demais foram descartados pois pertenciam a outras áreas do conhecimento. São eles: Melo (2019), Castro (2016), Silva (2017), Menezes (2019), Utsumi (2006).

Melo (2019), em sua dissertação com título “A integração do smartphone em sequência de ensino de estatística para o desenvolvimento do conhecimento tecnológico, pedagógico e do conteúdo", salienta que, com os avanços tecnológicos, a Estatística está em evidência no nosso cotidiano, mais frequentemente nas inúmeras informações apresentadas pela mídia e que nem sempre conseguem atingir todos os cidadãos, pois uma parte deles não sabe, de forma crítica, analisar e tomar decisões para o exercício da cidadania. Partindo dessa premissa, o autor busca, a partir da teoria do Conhecimento Tecnológico, Pedagógico e do Conteúdo (TPACK), analisar como os professores integram a tecnologia digital móvel dos smartphones ao ensino de Estatística sobre o Tratamento da informação. A metodologia se respalda no modelo BYOD (Bring Your Own Device) e na sequência de ensino contextualizada, seguindo o modelo PPDAC (Problema, Plano, Dados, Análise, Conclusão) como suporte estratégico didático para professores. Pedagogicamente, a autora ainda analisa o desenvolvimento das habilidades presentes na Base Nacional Comum Curricular (BNCC) e Prova Brasil referentes à pesquisa científica. $\mathrm{O}$ processo formativo ocorreu com quatro professores de Matemática dos anos finais do Ensino 
Fundamental, sendo que apenas os resultados de um professor foram considerados na pesquisa. O trabalho desenvolvido de maneira colaborativa e a cooperação aconteceram em conjunto com o projeto DESTAT (Desenvolvimento profissional de professores que ensinam Estatística), ao qual a pesquisa foi vinculada. Os resultados ampliaram o conhecimento com as tecnologias e sua aplicação no ensino de Estatística, de forma a integrar os smartphones no ensino de Estatística, através do uso de aplicativos e construção de formulários online. Segundo Melo (2019), o professor só consegue deixar o modelo tradicional de ensino quando é colocado em contato com novas práticas, como na tentativa de integrar o ensino e a aprendizagem com as tecnologias. No entanto, a obra aproxima pelo conteúdo a ser abordado no trabalho dessa pesquisadora e na metodologia da sala de aula invertida.

Castro (2016), em sua tese "Construção do conceito de covariação por estudantes do ensino fundamental em ambientes de múltiplas representações com suporte das tecnologias digitais", analisou o desenvolvimento de atividades em estudos relacionados à compreensão do conceito de covariação, conteúdo abordado no Ensino de Estatística. A pesquisa de intervenção foi realizada com estudantes do $6^{\circ}$ ano do Ensino Fundamental, dividida nas etapas do pré-teste, intervenção e pós-teste, sendo avaliados dois grupos: Grupo Controle (GC), com 15 alunos, e Grupo Experimental (GE), com 12 alunos. Sua aplicação foi realizada individualmente e sem uso do computador. Os dois grupos mantiveram aulas presenciais e apenas o grupo GE trabalhou com atividades que utilizavam tecnologias digitais (software Geogebra, recurso digital Equilibrando proporções, aplicativo online Cacoo, WhatsApp e blog). Constatou-se que os alunos que utilizaram tecnologia apresentaram, estatisticamente, rendimento superior aos outros. Desse modo, Castro concluiu que a tecnologia aliada ao ensino e a aprendizagem pode trazer resultados satisfatórios e, em consonância, é necessário atuar também na formação docente para o uso da tecnologia, de modo que ela seja ressignificada.

Silva (2017), na tese "A utilização da experimentação remota como suporte para ambientes colaborativos de aprendizagem" usou a filosofia da teia para definir o que designou de estratégia didático-matética, que é a forma de conhecer as necessidades matemáticas individuais dos alunos em meio à coletividade da sala de aula, em um empreendimento que busca construir uma cultura didática e construtivista, com o intuito de potencializar a aprendizagem matemática e suas formas de avaliar através de práticas educativas presenciais e online, com e sem o uso das tecnologias digitais. O autor explicita que a filosofia da teia é a teoria resultante de nossa prática, agregada a teorias psicológico-educacionais, que minimizam os obstáculos da aprendizagem humana e a operacionalização das Tecnologias Digitais da Informação e Comunicação, estabelecendo uma relação ao ensinoaprendizagem-avaliação. $\mathrm{O}$ autor utilizou a filosofia da teia, a qual articula a aprendizagem e a avaliação a partir de teorias psicológicas, em que o método ganha novos significados no processo ensino-aprendizagem-avaliação, despertando nos alunos o interesse por aprender conceitos matemáticos.

A pesquisa do autor apontou que o professor consegue criar um processo e utilizá-lo cotidianamente com os estudantes, conforme a didática da filosofia da teia. Desse modo, a pesquisa permeia ambientes virtuais de aprendizagem e o ensino a distância, trabalhando com um sistema de ensino híbrido.

Vale destacar que os conceitos teórico-metodológicos identificados nas pesquisas de Melo (2019), Silva (2017) e Vespasiano (2016) se aproximam quanto ao uso de tecnologia e o Conhecimento Pedagógico-Tecnológico de Conteúdo (TPACK).

Menezes (2019), em sua dissertação "Game para smartphones e ambientes de aprendizagem", propõe o ensinoaprendizagem de Matemática por meio de um game para smartphones, o aplicativo JobMath. Pautado na classificação de ambientes de aprendizagem descrita por Skovsmose (2000 apud Menezes, 2019), ele diferencia o mundo da realidade material (sem as tecnologias) e a realidade virtual (com as tecnologias) para analisar dois paradigmas, descritos como o dos exercícios e o dos cenários para investigação. A partir deles, ocorre o surgimento de três referências, sendo elas a Matemática Pura, a semirrealidade e a realidade, gerando um total de 6 diferentes ambientes. Para analisar esses ambientes totalmente virtuais e a Matemática construída e praticada pelos estudantes, Menezes utilizou a perspectiva da Modelagem Matemática através de uma prática que valoriza a voz do estudante, por meio da aplicação de um experimento de ensino com questões e tarefas práticas. Conclui-se que o surgimento de um cenário cibernético para investigação, onde os alunos se envolvem em atividades, proporciona diversas tomadas de decisões para as resoluções.

Concluímos que, para o autor, quando as tecnologias são inseridas na sala de aula o resultado advindo do uso delas evidencia a aprendizagem. Assim, conclui que precisamos avançar para que o professor esteja apto a trabalhar com as tecnologias aliadas ao ensino e a aprendizagem.

Utsumi (2016), em sua tese "Um estudo sobre os saberes formativos do formador de professores de Matemática do curso de Licenciatura em Pedagogia", objetivou estudar os saberes necessários dos docentes formadores, docentes para a formação inicial dos professores de Matemática e professores de Pedagogia. A pesquisa buscou quais eram as necessidades do ensino dos conteúdos matemáticos e as abordagens metodológicas no contexto do Ensino da Matemática, tendo em vista a didática para o ensino fundamental e sua conexão com a formação de professores. Por meio de questionários e realização de entrevistas, tanto com os professores formadores como com os estudantes de pedagogia e matemática, os resultados indicam a necessidade de se aprofundar no domínio 
dos conteúdos matemáticos de ensino. Nesse sentido, a análise dos dados da pesquisa confirmou a necessidade constante de formação matemática continuada por parte do formador de professores.

Desse modo, a pesquisa da autora destacou a necessidade constante da formação continuada, porém não investigou a integração do uso das TIC no ensino dos conteúdos matemáticos.

Continuamos a busca, agora com os termos:

3) Tecnologia digital + ensino de estatística + aula online + formação professor, dos quais resultaram 2 trabalhos. Sendo 1 deles, Nikolay (2018) aproveitado no corpus, uma vez que a outra produção identificada foi descartada por desenvolver atividades no ensino jurídico, com o uso de tecnologia, pertencendo assim, a outra área do conhecimento.

Nikolay (2018), em sua dissertação "Uso de tecnologias educacionais nos anos finais do ensino fundamental: indicadores para formação de professores", propõe indicadores para a formação continuada de professores dos anos finais do ensino fundamental com o uso de tecnologias educacionais. Por meio de entrevistas semiestruturadas e aplicação de um questionário online, a autora busca identificar as tecnologias utilizadas pelos docentes e, com o oferecimento de uma oficina experimental aliada a tecnologias educacionais, promover ferramentas de mediação pedagógica no processo ensino-aprendizagem. A pesquisa de natureza qualitativa e exploratória foi realizada com 49 professores, dos quais apenas 5 participaram da entrevista semiestruturada. A oficina experimental proposta introduziu o conceito de tecnologias educacionais e metodologias ativas na prática docente, tais como "ensino híbrido, sala de aula invertida, gamificação, redes sociais, ensino móvel e plataforma Google, gravação e edição de um pequeno vídeo (YouTube), com a publicação na plataforma Google e a criação de uma atividade a ser utilizada em sua prática docente. Com isso, Nikolay concluiu que as ferramentas tecnológicas são importantes para o processo ensino-aprendizagem, já que os conceitos utilizados foram a gamificação, o ensino móvel e redes sociais. Porém, a oficina não abordou um conteúdo específico de Matemática com o uso de tecnologias.

As buscas foram feitas com os seguintes termos: 4) Ensino híbrido + aula remota + tecnologia, com localização de duas publicações, sem aderência com está pesquisa; 5) Tecnologia digital + ensino de estatística + aula online + formação docente, dos quais resultaram 2 publicações descartadas; 6) Tecnologia + ensino de estatística + aula online + formação, que localizou 6 publicações, todas descartadas; 8) Tecnologia + aula remota + formação docente, tendo como resultado a localização de 21 publicações, todas descartadas, e 9) Ensino híbrido + aula remota + formação docente + ensino de estatística, sem qualquer resultado.

Do conjunto de 47 produções acadêmicas, observamos que elas se distribuem entre 23 Instituições de Ensino Superior. Entre elas se destaca a Universidade Estadual
Paulista Júlio de Mesquita Filho (UNESP), pelo número de pesquisas com os enfoques mencionados (Formação docente, Ensino de Estatística, Tecnologias digitais), tendo 5 pesquisas concluídas. Na sequência, com 4 pesquisas concluídas cada uma, estão as seguintes Instituições: a Universidade Federal do Triângulo Mineiro (UFTM), a Universidade Federal de Santa Catarina (UFSC), a Universidade Federal do Rio Grande do Sul (UFRGS) e a Universidade Metodista de São Paulo (UMESP). As demais Instituições seguem representadas no Quadro 1.

Quadro 1 - Número de trabalhos publicados por IES

\begin{tabular}{|l|c|}
\hline \multicolumn{1}{|c|}{ Instituição } & Produções \\
\hline $\begin{array}{l}\text { Universidade Estadual Paulista Júlio de Mesquita } \\
\text { Filho }\end{array}$ & 5 \\
\hline Universidade Federal do Triângulo Mineiro & 4 \\
\hline Universidade Federal de Santa Catarina & 4 \\
\hline Universidade Federal do Rio Grande do Sul & 4 \\
\hline Universidade Metodista de São Paulo & 4 \\
\hline $\begin{array}{l}\text { Pontifícia Universidade Católica do Rio Grande } \\
\text { do Sul }\end{array}$ & 3 \\
\hline Universidade São Paulo & 3 \\
\hline Universidade Federal de Itajubá & 2 \\
\hline Universidade Federal de Pernambuco & 2 \\
\hline Universidade Federal do Ceará & 2 \\
\hline Universidade Federal do Rio de Janeiro & 2 \\
\hline Centro Universitário Internacional Uninter & 1 \\
\hline $\begin{array}{l}\text { Instituto Federal de Educação, Ciência e } \\
\text { Tecnologia do Amazonas }\end{array}$ & 1 \\
\hline Universidade do Rio Grande do Sul & 1 \\
\hline Universidade Estadual de Feira de Santana & 1 \\
\hline Universidade Estadual de Maringá & 1 \\
\hline Universidade Estadual de Mato Grosso do Sul & 1 \\
\hline Universidade Estadual de Goiás & 1 \\
\hline Universidade Federal de Alagoas & 1 \\
\hline Universidade Federal de Goiás & 1 \\
\hline Universidade Federal de Santa Maria & 1 \\
\hline Universidade Federal do Rio Grande do Norte & 1 \\
\hline Universidade Federal Rural do Rio de Janeiro & \\
\hline Total & 1 \\
\hline
\end{tabular}

Fonte: Dados da pesquisa.

Quanto à fundamentação teórica encontrada nas oito pesquisas analisadas, destacou-se a do Conhecimento Pedagógico-Tecnológico de Conteúdo(TPACK), desenvolvida por Mishra e Koehler, a partir de 2006. As demais correntes teóricas estão apresentadas no Quadro 2.

Quadro 2 - Referencial Teórico das obras analisadas

\begin{tabular}{|l|c|}
\hline \multicolumn{1}{|c|}{ Referencial Teórico-Metodológico } & Pesquisas \\
\hline TPACK & 2 \\
\hline Ensino Híbrido & 1 \\
\hline Van Hiele & 1 \\
\hline Filosofia da teia & 1 \\
\hline Modelagem Matemática & 1 \\
\hline Teoria dos Campos Conceituais & 1 \\
\hline Saberes Docentes & 1 \\
\hline Total & 8 \\
\hline
\end{tabular}

Fonte: Dados da pesquisa. 
Com relação aos métodos de pesquisa das pesquisas analisados, destacamos a Pesquisa Qualitativa e o Teste diagnóstico.

Quadro 3 - Distribuição dos métodos de pesquisa utilizados

\begin{tabular}{|l|c|}
\hline \multicolumn{1}{|c|}{ Metodologia } & Quantidade \\
\hline Abordagem mista & 1 \\
\hline Investigação Matemática em sala de aula & 1 \\
\hline Pesquisa colaborativa & 1 \\
\hline Pesquisa de Intervenção & 1 \\
\hline Sequência de Ensino & 1 \\
\hline Pesquisa-ação & 1 \\
\hline Cenários para Investigação & 1 \\
\hline Pesquisa Qualitativa e Exploratória & 1 \\
\hline Total & $\mathbf{8}$ \\
\hline
\end{tabular}

Fonte: Dados da pesquisa.

Quanto às obras selecionadas, encontramos apenas duas pesquisas quando utilizamos os termos de busca "ensino de estatística", associados a tecnologias digitais, ensino híbrido, formação docente.

No que diz respeito à tendência de se ensinar com tecnologia, vislumbramos nas pesquisas analisadas atividades direcionadas à prática docente nas quais o professor é motivado externamente a conhecer e aplicar atividades com os alunos.

\section{Algumas Considerações}

Este artigo apresenta revisão de literatura com base em mapeamento de pesquisas que geraram dissertações e teses publicados na Biblioteca Digital Brasileira de Teses e Dissertações (BDTD), com foco na Formação Docente, no uso de tecnologias nos processos de ensino e de aprendizagem e no Ensino de Estatística.

A partir do mapeamento foram identificadas investigações que versam sobre a Formação de Professores, principalmente no que se refere à formação continuada e, mais precisamente, nos trabalhos que enfatizam o uso das TIC. Percebemos que os pesquisadores buscam implementar "cursos" ou "sequências didáticas" que transformam o ambiente escolar em um ambiente de aprendizagem, de modo distinto do modelo tradicional de ensino.

Como conclusão identificamos nas pesquisas analisadas a constatação de que a formação continuada do professor de Matemática tem se apresentado insuficiente e a sugestão de que sejam oferecidos cursos como alternativa relacionada às deficiências no uso das tecnologias aplicadas à educação.

Tendo em vista que nas buscas realizadas verificamos que muitas produções adentram outras áreas do conhecimento, o presente artigo se limita ao estudo da Área da Educação Matemática e do Ensino de Estatística correlacionadas ao uso das tecnologias na prática do ensino e da aprendizagem. Disponibilizamos no Anexo 1 os títulos das pesquisas identificadas e que ficaram fora do escopo dessa revisão, de modo a ser útil para outros pesquisadores.

Com relação à Formação de Professores e à Formação
Continuada, identificamos a recomendação de Vespasiano (2016) sobre a necessidade de inclusão da TIC no processo de formação dos professores. Além disso, as pesquisas analisadas apontam para a existência de ganho significativo para os envolvidos no processo (professores e/ou alunos).

No momento atual, em que a humanidade atravessa um período de pandemia, devido à disseminação do novo Coronavírus, as TIC se tornaram uma das principais ferramentas de interação entre as pessoas, inclusive permitindo a continuidade de atividades na área da Educação, conectando professores e alunos. O que vem pela frente são tecnologias novas e desconhecidas, e cabe a novos pesquisadores desbravar o universo tecnológico e encontrar novas ferramentas capazes de facilitar o processo ensino-aprendizagem.

\section{Referências}

Abar, C. A. A. P \& Rodrigues, R. U. (2020). GeoGebra e Sala de Aula Invertida: uma possibilidade para a formação continuada de professores no contexto da Matemática. Ensino da Matemática em Debate, 7, 68-82. doi:10.23925/2358-4122.

Baur, A. P. (2017). Investigação Matemática na aprendizagem da Geometria: conexões entre quadriláteros, triângulos e transformações geométricas (Dissertação de Mestrado, Universidade Federal do Rio Grande do Sul).

Castro, J. B. (2016). Construção do conceito de covariação por estudantes do ensino fundamental em ambientes de múltiplas representações com suporte das tecnologias digitais (Tese de Doutorado, Universidade Federal do Ceará).

Gil, A. C. (2002). Como elaborar projetos de pesquisa. São Paulo, Brasil: Atlas.

Gonçalves, E. H \& Marco, F. F. (2020). As implicações metodológicas para a formação do docente da abordagem de Tecnologias Digitais em um curso de Licenciatura em Matemática na modalidade a distância. Educação Matemática Pesquisa, 22, 558-583. doi: 10.23925/1983-3156.

Lobo da Costa, N. M. \& Prado, M. E. B. B. (2011, julho). Formação Continuada do Professor de Matemática - o trabalho colaborativo e o desenvolvimento profissional docente. In: Anais do 13. Conferência Interamericana de Educação Matemática (1-12), Recife, PE.

Maltempi, M. V. (2008). Educação matemática e tecnologias digitais: reflexões sobre prática e formação docente. Acta Scientiae, 10, 59-67.

Melo, E. M. (2019). A integração do smartphone em sequência de ensino de estatística para o desenvolvimento do conhecimento tecnológico, pedagógico e do conteúdo (Dissertação de Mestrado, Universidade Federal do Rio Grande do Norte).

Menezes, B. S. (2019). Game para smartphones e ambientes de aprendizagem. (Dissertação de Mestrado em Ensino de Matemática, Universidade Federal do Rio Grande do Sul).

Nikolay, J. R. (2018). Uso de tecnologias educacionais nos anos finais do ensino fundamental: indicadores para formação de professores (Dissertação de Mestrado, Centro Universitário Internacional Uninter).

Rolando, L. G. R. (2017) Um exame da percepção de professores de Biologia acerca de suas bases de Conhecimento Tecnológico Pedagógico do Conteúdo (Tese de Doutorado, Instituto Oswaldo Cruz). Disponível em:

https://www.arca.fiocruz.br/bitstream/icict/23820/2/luiz_ 
rolando ioc dout 2017.pdf

Santos, L. M. M. \& Alves, M. A. (2020). Formação inicial de professores de matemática: mapeamento teórico. REnCiMa, 11, 110-130. doi: 10.26843/rencima.v11il.2262

Silva, H. R. M. (2017). A avaliação em matemática em forma de teia com assistência contínua ao estudante (Dissertação de Mestrado em Ensino de Ciências e Matemática, Universidade Federal de Alagoas).
Utsumi, L. M. S. (2016). Um estudo sobre os saberes formativos do formador de professores de Matemática do curso de Licenciatura em Pedagogia (Tese de Doutorado, Universidade Metodista de São Paulo).

Vespasiano, L.M. (2016). As tecnologias digitais da informação e comunicação na docência universitária nos cursos de administração e ciências contábeis (Dissertação de Mestrado, Universidade Federal do Triângulo Mineiro).

Anexo 1 - Resultados da busca que foram descartados por estarem fora do escopo desta revisão

\begin{tabular}{|c|c|c|}
\hline Autor & Título das Produções descartadas & Ano \\
\hline Aline Coêlho dos Santos & $\begin{array}{l}\text { Integração de tecnologia na educação básica: um estudo de caso nas aulas de biologia } \\
\text { utilizando laboratórios on-line }\end{array}$ & 2018 \\
\hline Ana Paula Amorim da Silva & $\begin{array}{l}\text { Potencial pedagógico do sensoriamento remoto nas escolas de educação básica da região } \\
\text { metropolitana de Feira de Santana }\end{array}$ & 2013 \\
\hline $\begin{array}{l}\text { Ana Paula Noemy Dantas } \\
\text { Saito Borges }\end{array}$ & O currículo do Ensino Técnico integrado ao Ensino Médio: desafios e perspectivas & 2018 \\
\hline Ana Tereza Vendramini Reis & $\begin{array}{l}\text { A importância das TICS e da Educação como processo comunicacional dialógico no Ensino } \\
\text { Superior: um estudo da Universidade Federal de Mato Grosso do Sul }\end{array}$ & 2016 \\
\hline Antônio Marcos de Andrade & $\begin{array}{l}\text { A geometria plana e espacial no ensino médio: um contexto formal e não formal como espaço } \\
\text { de aprendizagem }\end{array}$ & 2019 \\
\hline Carine Heck & $\begin{array}{l}\text { Integração de tecnologia no ensino de física na educação básica: um estudo de caso utilizando } \\
\text { a experimentação remota móvel }\end{array}$ & 2017 \\
\hline $\begin{array}{l}\text { Celsa Raquel Villaverde } \\
\text { Melgarejo }\end{array}$ & $\begin{array}{l}\text { Efetividade de uma intervenção educativa para promoção da cultura de notificação de } \\
\text { incidentes em saúde }\end{array}$ & 2018 \\
\hline Cristiane da Costa Lobato & $\begin{array}{l}\text { Estratégias metodológicas de ensino-aprendizagem na educação a distância: um estudo de } \\
\text { caso no Instituto Federal do Amapá }\end{array}$ & 2016 \\
\hline Daniela Fiorini da Silva & $\begin{array}{l}\text { Concepções sobre ciência e tecnologia de professores de ciências em formação continuada } \\
\text { e seus planos de ensino }\end{array}$ & 2017 \\
\hline Demian Oliver Vidal & Vídeos introdutórios sobre "redação de pedidos de patentes" & 2019 \\
\hline Diógenes Gewehr & $\begin{array}{l}\text { Tecnologias Digitais de Informação e Comunicação (TDICs) na escola e em ambientes não } \\
\text { escolares }\end{array}$ & 2016 \\
\hline Dulce Léia Garcia Pazini & $\begin{array}{l}\text { Formação de professores no uso de sistemas de informação geográfica no ensino fundamental } \\
\text { e médio }\end{array}$ & 2008 \\
\hline Érica Ferreira Marques & $\begin{array}{l}\text { A utilização do processo de avaliação on-line como apoio ao ensino presencial: } \\
\text { desenvolvimento e análise junto ao laboratório virtual de estatística aplicada à administração } \\
(\text { LaVie })\end{array}$ & 2007 \\
\hline $\begin{array}{l}\text { Flávio Henrique Lara da } \\
\text { Silveira Zaghi }\end{array}$ & Educação Física Escolar e a prova do ENEM: convergências e divergências & 2014 \\
\hline Franciele Eunice de Araújo & $\begin{array}{l}\text { Educação Cartográfica: uso de imagens de sensoriamento remoto e mapas antigos no estudo } \\
\text { da ocupação Candeias e Barra de Jangada }\end{array}$ & 2017 \\
\hline $\begin{array}{l}\text { Geiza Basualdo Bogado } \\
\text { Pereira }\end{array}$ & O estudante de EAD (Educação a distância): um estudo de perfil e interação geracional & 2015 \\
\hline Gustavo Marques Borges & $\begin{array}{l}\text { O uso do sensoriamento remoto como recurso didático nas aulas de geografia do ensino } \\
\text { médio: desafios e possibilidades para uma ação pedagógica }\end{array}$ & 2015 \\
\hline $\begin{array}{l}\text { Herculano Henriques } \\
\text { Chingui Chitungo }\end{array}$ & $\begin{array}{l}\text { O uso de laboratórios remotos no ensino de Física na Educação Básica: estudo de caso na } \\
\text { escola em rede pública }\end{array}$ & 2018 \\
\hline $\begin{array}{l}\text { Ivanildo Fabricio de } \\
\text { Oliveira }\end{array}$ & Raios x no Ensino Médio via acesso remoto na perspectiva da aprendizagem significativa & 2016 \\
\hline Jéssica Miranda e Souza & $\begin{array}{l}\text { Um estudo sobre um experimento controlado remotamente sobre Radiações Ionizáveis no } \\
\text { contexto do Ensino Médio }\end{array}$ & 2018 \\
\hline $\begin{array}{l}\text { Jorge Henrique de } \\
\text { Magalhães Sasso Sciascio }\end{array}$ & Aprendendo xadrez: entre a abordagem metodológica presencial e a tecnológica & 2014 \\
\hline Juarez Bento da Silva & $\begin{array}{l}\text { A utilização da experimentação remota como suporte para ambientes colaborativos de } \\
\text { aprendizagem }\end{array}$ & 2006 \\
\hline Juliana Mariani Santos & $\begin{array}{l}\text { Avaliação de uma oficina sobre biomas brasileiros junto à licenciandos em ciências } \\
\text { biológicas, utilizando o sensoriamento remoto como ferramenta }\end{array}$ & 2009 \\
\hline José Pereira Emiliano & Javal - Modelo de ambientes de avaliação remota multiagente baseada em tutores embarcados & 2002 \\
\hline Karen Henn Gil & Aprendizagem de geometria plana por meio de técnicas de sensoriamento remoto & 2012 \\
\hline
\end{tabular}




\begin{tabular}{|c|c|c|}
\hline Luisete Moraes Bandeira & $\begin{array}{l}\text { Formação a distância para conselheiros de alimentação escolar: elaboração, aplicação e } \\
\text { avaliação }\end{array}$ & 2012 \\
\hline $\begin{array}{l}\text { Luiz Eduardo Alves de } \\
\text { Siqueira }\end{array}$ & Ensino Jurídico a Distância: Reflexões sobre sua viabilidade no âmbito do Mercosul & 2015 \\
\hline $\begin{array}{l}\text { Luiz Gustavo Ribeiro } \\
\text { Rolando }\end{array}$ & $\begin{array}{l}\text { Um exame da percepção de professores de Biologia acerca de suas bases de Conhecimento } \\
\text { Tecnológico Pedagógico do Conteúdo. }\end{array}$ & 2017 \\
\hline Marcelo Chanes & $\begin{array}{l}\text { Conhecimento assimilado e percepção da mediação pedagógica em ambientes de } \\
\text { aprendizagem }\end{array}$ & 2013 \\
\hline Márcia Regina Pires & As competências do professor da Educação à Distância & 2016 \\
\hline Marcos Pereira dos Santos & LABVAE: uma solução para experimentação de aprendizagem eletrônica & 2014 \\
\hline $\begin{array}{l}\text { Maria Angélica Muniz } \\
\text { Gomes }\end{array}$ & Abordagem investigativa da digestão e alimentação com estudantes no Ensino Médio & 2019 \\
\hline Marilena Estrella Facuri & $\begin{array}{l}\text { Mediação pedagógica: uma relação de construção e descobertas no ambiente virtual de } \\
\text { aprendizagem na modalidade semipresencial }\end{array}$ & 2011 \\
\hline Nayara Poliana Massa & $\begin{array}{l}\text { Mapeamento do pensamento computacional por meio da ferramenta scratch no contexto } \\
\text { educacional brasileiro: análise de publicações do Congresso Brasileiro de Informática na } \\
\text { Educação entre } 2012 \text { e } 2017\end{array}$ & 2019 \\
\hline Rafael Gustavo Rigolon & $\begin{array}{l}\text { Analogias quantitativas como estratégia didática na formação inicial de professores de } \\
\text { Biologia e Física }\end{array}$ & 2016 \\
\hline Rogério Ambrosio & $\begin{array}{l}\text { Analisando a relação dos volumes de exportação e de importação, PIB, taxas de câmbio e } \\
\text { inflação no período de } 2004 \text { a } 2014\end{array}$ & 2015 \\
\hline $\begin{array}{l}\text { Sônia Maria Gonçalves da } \\
\text { Silva }\end{array}$ & Os recursos geotecnológicos como possibilidade pedagógica na educação infantil & 2013 \\
\hline $\begin{array}{l}\text { Teresa Cristina Lopes } \\
\text { Fabrete }\end{array}$ & $\begin{array}{l}\text { A influência das práticas pedagógicas docentes e das barreiras discentes sobre o } \\
\text { desenvolvimento da criatividade do futuro administrador }\end{array}$ & 2015 \\
\hline Viviane de Oliveira Kfouri & Fi: o número de ouro & 2014 \\
\hline
\end{tabular}

